\title{
Taxes and the Structure of Production
}

Abstract - In Austrian theory, the business cycle is caused by expansive monetary policy, which artificially lowers the interest rate below equilibrium rates, necessarily lengthening the structure of production. Can tax alterations also cause an Austrian business cycle? Only if they affect time preference rates, the determinant of the shape of the Hayekian triangle. It is the contention of this paper that changes in taxes possibly can (but need not) impact time preference rates. Thus there may be a causal relation between fiscal policy and the business cycle, but this is not a necessary connection, as there is between monetary policy and the business cycle. This is contentious, since some Austrians argue that there is a praxeological link between tax policy and time preference rates.

Key words - Structure of production, Hayekian triangle, taxes, roundaboutness, time preference

7EL classifications - E2, E3, E4, E6, H2

;

\section{1. - Introduction}

The objective of this paper is to explore, from an Austrian economic perspective, the nexus between the structure of production and taxes. There are numerous Austrian studies of taxation [ROTHBARD, 1970, 1977] but these do not focus on the implications for the structure of production. Similarly, works on taxes by non-Austrians are abundant ${ }^{1}$, but these do not even address the implications for the structure of production ${ }^{2}$, albeit they do not address specifically the topic we wish to investigate.

Austrians have frequently focused on the structure of production and the concept of roundaboutness [BÖHM-BAWERK, 1959; HAYEK, 1932, 1975;

*E-mail: wblock@mail.uca.edu; tel.+1.501.4505355

'See for example Browning [1979], Browning and Johnson [1984], Buchanan [1984], Buchanan and Brennan [1980], Due [1963], Feldstein [1980], Musgrave and Musgrave [1959], Shoup [1969]. For an Austrian critique of some of these neoclassical perspectives, see Block [1989, 1992, 1993].

${ }^{2}$ Indeed, this is probably as good a short hand definition of the praxeological school as one is likely to obtain. 
ROTHBARD, 1970, chs. 6 and 7; 1975; vON MISES, 1966, chs. 18-20], but their analyses have always been directed to the problems of the business cycle, or inflation, not taxes. The original aspect of this paper, thus, is to directly probe the relationship between taxes, on the one hand, and the structure of production, on the other [MACHLUP, 1935; KALDOR, 1932] ${ }^{3}$.

\section{2. - Theoretical background}

\section{1 - Time preference rates}

It shall be our contention that taxes affect the structure of production, or the shape of the investment triangle (see Appendix 1) insofar, and to the degree, that they impact on time preference rates. If taxes did not alter the rate of preference of present over future, then, according to the view espoused here, they would leave unchanged the structure of production. The reason for taking this stance is obvious; since the rate of time preference in an economy is the sole determinant of the shape of the triangle [ROTHBARD, 1970] it is inconceivable that any tax could alter the latter without doing so to the former as well.

This, however, brings us to an immediate problem. For there is no necessary relationship between a tax and time preference. To be sure, taxes, $\mathrm{ce}$ teris paribus, lower incomes. And income, or wealth, or salary, or take-home pay tends to be inversely related to time preference rates. That is, the richer is a person, the more likely he is to have a low time preference rate, and if a particular person gains wealth, the rate of his preference for present over future is likely to fall. But this need not be the case; for example, a person could become poorer, and yet undergo a decrease in his rate of time preference $^{4}$. Thus, we cannot derive an apodictically certain relationship between the shape of the triangles and the effect of taxes; any association we succeed in uncovering cannot be any stronger than this mere tendency, or correlation; we cannot, in other words, derive any necessary relationship between taxation and the structure of production.

${ }^{3}$ I owe these citations to Richard Ebeling.

4 There would appear to be only one exception to this general rule. At extremely low levels of wealth, literally at subsistence levels, if a person suffers a loss of income his time preference for the present must rise. And since if he does not survive, he will no longer be part of the economy, we may safely ignore those for whom this is not true. See Rothbard [1970, pp.329,330,380,381].

\section{2 - Subsidies}

$\rightarrow$

There is also a second difficulty before we even begin. Our analysis shall be incomplete if we ignore the government subsidies which flow from the taxes, and are only made possible by them. If taxes were the sole phenomena to be considered, and we could safely ignore the expenditure side of the equation, our conclusions would be direct and straightforward: taxes lower incomes. A fall in income is (historically, or empirically, or statistically) linked with higher time preference rates; these, in turn, are correlated with a flatter triangle. Hence, taxes flatten triangles, QED.

In what way, however, shall we take account of subsidies? One possibility is to assume that the government budget is balanced, and that taxes thus equal subsidies. If we make the further assumption that each taxpayer is fully compensated by the government subsidies spent in his behalf, we might conclude that fiscal policy has no effect on the triangle; this would be because in the present scenario, any incipient flattening of the production structure due to taxes is exactly counterbalanced by its lengthening, due to offsetting subsidies.

But there are grave difficulties with such a model. First, it would be practically impossible for government to spend the consumers' money in their behalf exactly as they themselves would have, in the absence of the tax and subsidy. But unless this is done, the fiscal process would leave people poor$\mathrm{er}^{5}$, and thus have a flattening effect on the triangle. Secondly, even if the state could somehow contrive this happy situation, it would still cost more than if government had not engaged in any such policy. Again, we have the same result: the structure of production becomes flatter. But even if government could somehow engineer this outcome, why engage in such a financially meaningless transaction in the first place? It would be null and void ${ }^{6}$ in any case.

5 We know this because otherwise the people could have done this for themselves. Why should they be forced to pay taxes, if they were truly made no worse off: See Rothbard [1977].

${ }^{6}$ See Calhoun $[1953$, p. 16]. Rothbard [1978, p. 53] states: «Few, comparatively, as they are, the agents and employees of the government constitute that portion of the community who are the exclusive recipients of the proceeds of the taxes. Whatever amount is taken from the community in the form of taxes, if not lost, goes to them in the shape of expenditures or disbursements. The two - disbursement and taxation - constitute the fiscal action of the government. They are correlatives. What the one takes from the community under the name of taxes is transferred to the portion of the community who are the recipients under that of disbursements. But as the recipients constitute only a portion of the community, it follows, taking the two parts of the fiscal process together, that its action must be unequal between the payers of the taxes and the recipients of their proceeds. Nor can it be otherwise; unless what is collected from each individual in the shape of es shall be returned to him in that of disbursements, which would make the process mugator and es shall be returned to him in that of disbursements, which would make the process nugatory and
absurd [...]» (emphasis added). 
Another possibility, a more realistic one, is that the tax subsidy program worsens the citizenry's financial position, compared to what it would have been in the complete absence of any fiscal policy. If so, then the increase in time preference associated with the falling income because of taxes (which flattens the triangle) outweighs the fall in time preference of the rising income $e^{7}$ because of subsidies (which lengthens the triangle). The net result would be a shortening of the roundaboutness of production.

\section{3 - Consumption and expenditure}

So far, we have been implicitly assuming that taxes can come at either the expense of higher order or lower order goods, and, obversely, that subsidies can be used to supplement the upper or lower reaches of the triangle. While this is sensible with regard to taxes, it is now time to call into question this assumption about subsidies. In a penetrating and incisive analysis, Rothbard has shown that no matter what the specifics are, all government expenditure is necessarily consumption; none of it can be investment [ROTHBARD, 1970, pp. 835-836].

On the face of it, this is a dubious proposition. Does not the state build factories, roads, airports, apartment blocks, dams, railroads which, if done in the private sector, would almost automatically be classified as investment? To be sure the government does engage in such activities, but this does not alter the fact that these expenditures are necessarily consumption, not investment. And the reason for this counter-intuitive categorization may be found in Austrian capital theory and subjectivism.

While an orthodox economist may take one look at an airport, for example, and immediately classify it as investment, the Austrian must not be fooled by the chemical, physical, mechanical or engineering aspects of the facility; he must probe beneath the surface, and ascertain the purposes of such an expenditure. In the private sector, the purpose of an airport, or any other such

${ }^{7}$ It is extremely risky to claim that people's incomes rise as a result of subsidies, unless these It is extremely risky to claim that pash grants: the exact type of payment exacted from them in taxes. For the are "free" tennis court. First f all, people of all, people might not uney it collected in taxes algerous neighborhood. Under these conditions, the state spent the maxes alright, but none of the people in whose names it was ostensibly spent benefted from it. But suppose that it is well located, and widely used. From this we can deduce only that the people value it more highly than the zero cost they must pay for utilization; we are not entitled to conclude that
they value it at any positive price. capital good is clear: it is to make profits, by providing consumers ${ }^{8}$ with a service value, and for which they are willing to pay. In contrast, a politically-created airport need have no such goal. And, typically, it does not. Rather, the purpose is usually to buy votes, or to enhance political prestige, or for the sheer desire, on the part of the politician, to see an airport erected on a particular cite. It may be located so far away from the consumers that it is hardly used at all?.

In any case, the wishes of the consumer are all but irrelevant. But the whole point of investment is, ultimately, consumer satisfaction. Government expenditure, safe from the wrath of the final customer, thus cannot be considered investment.

Given this analysis, our earlier view is buttressed even more. For if fiscal policy inherently shortens the roundaboutness of production when government expenditure is considered either investment or consumption, the triangle is further flattened when cognizance is taken of the fact that these funds must be categorized as extreme lower order goods.

\section{3. - Specific tax policies}

It is now time to narrow the analysis, and focus on specific taxes. We shall consider impositions based on savings and investment, and on property and wages. As well, we shall explore the implications of progressive, proportional and regressive taxes.

\section{1 - Savings and investment}

At first glance, it will appear obvious that a tax on savings would shorten the structure of production, and one on consumption would lengthen it. However intuitive, this is not the conclusion we shall reach ${ }^{10}$. Let us consider each case in turn, taking consumption-based taxes first.

On the one hand, net income will fall when this tax is collected. This will lead to a rise in time preference rates, and thus a flatter triangle. Call this the

${ }^{8}$ Undoubtedly, airports serve other manufacturers and capitalists, as well as consumers. But if they, too, are private, their ultimate concern is with the consumer.

"See the case of Mirabel Airport, in Canada. In a real sense this "investment," and others like it, may be regarded as the economic equivalent of the Egyptian pyramids - only with vastly higher upkeep costs.

${ }_{10}$ For a bibliography of the orthodox or mainstream debate over the impact of social security legislation on savings, see Ferrara [1980]. 
income effect. On the other hand, the tax impacts specifically on consumption. Therefore, consumption will tend to fall, and savings to rise. This is equivalent to a fall in time preference, or to a lengthened triangle. Call this the substitution effect.

Given that the income and substitution effects lead us in opposite directions, we are in no position to say what impact the consumption tax will have on the structure of production. This will depend on the relative strengths of the two effects, and this is undeterminable. So we have an ambiguous result.

Now let us run through the exercise for the savings-based tax. First, the income effect again gives us the result that the period of roundaboutness shall be shortened. After all, income has fallen, and this we have agreed to count as a rise in time preference. But here, the substitution effect runs in the same direction. A tax on savings will lower savings, relątive to consumption. This, too, is equivalent to a higher time-preference rate, and thus leads, also, to a flatter triangle. In this case, unlike that for consumption, our result does not depend upon which of two effects is larger; both lead us in the same direction, and thus we have an unambiguous conclusion.

However, we cannot apodictically infer that savings taxes shorten production structures. This conclusion is only as good as our assumptions, and, it will be remembered, that except at exceedingly low (subsistence) standards of living, we are not entitled to posit the direction in which a lower income will impel the time preference rate. Our view that time preference and wealth levels are inversely related (the wealthier the person, the lower the time preference) is merely a broadly based empirical or statistical generalization. We can, however, apodictically infer a weaker conclusion; i.e., that other things equal, a tax on saving will tend to flatten the structure of production more than will one on consumption. This follows from the fact that both income and substitution effects led us in the flatter direction for savings taxes, while only an ambiguous result was derivable in the case of consumption.

\section{2 - Property and wage taxes}

For the analysis of these two levies, we shall employ the additional broadly based empirical generalization that capital or property owners have lower time preferences than do those who offer labor services to the market in return for wages.

With this assumption, we arrive at an analysis similar to that obtained in the previous case. As before, the income effect for either capital or payroll taxes leads towards a shorter duration for the production process. This is because with less after tax funding, the individual is presumed to raise his time preference rate. And the substitution effect in the case of property taxes leads in the same direction; for here the tax hits especially hard those who are assumed to have lower time preference rates, raising the rate, on average, for the entire society. However, with regard to payroll taxes, the situation is otherwise. In this case the tax is directed mainly at those who are assumed to have higher than average tax rates; in reducing their income; this substitution effect would tend to lower the average time preference rate, and thus to lengthen the structure of production.

So, while we can derive a clear move toward decreasing roundaboutness from capital taxes, the results of capital taxes are ambiguous. But this statement cannot be made apodictically, given the uncertainty of our basic premises. The only reasonably certain conclusion which emerges is that levies on property will more likely reduce roundaboutness than will those on wages and salaries.

\section{3 - Progressivity}

Taxes can be divided into those which are progressive, proportional and regressive; this distinction, too, has implications for the structure of production, because of the differential effects on the consumption/savings choice.

Let us consider progressivity, for example. Taxes of this type impinge most heavily on the rich ${ }^{11}$, and the rich are assumed to have the lowest time preference rates. This implies that the triangle will be flatter, since the result of the actions of the low time preference rich people is only compatible with an elongated structure of production triangle.

At the other end of the spectrum are regressive taxes, which impact relatively more heavily on the poor. But those at the lower end of the income or wealth scale are presumed to have high time preferences, which would otherwise lead to a flattened production structure. Since they now have less wherewithal than before to register their preferences, the triangle will be lengthened as a result of this type of tax. Proportional taxes would occupy something of a middle ground between the progressive and the regressive.

1" We are also assuming, throughout this analysis, that taxes are not shifted, and not evaded. We do so on the division of labor grounds that such complications would take us too far afield. If this seems too heroic an assumption, the present discourse can be interpreted as applying to that part of the tax system which is not shifted, nor evaded. 


\section{4. - Concluding remarks}

What are the public policy implications which emerge from this study? If the goal is to promote a lengthened structure of production, then regressive the goal is to promote a lengthene ones, a tax on consumption is better than one on savings, and wherever possible taxes on wages and salaries should be one on savings, those on capital and property. If, however, the aim is to reduce substituted for those on capital and property. It is important to emphasize the point that neither value judgment can be It is important to emphasize the prom. As practitioners of a value free science [MISES, 1969, pp. 26-27], Austrian economists must studiously avoid any and [MIsES, 1969, pp. 26-2], Aus judgements. One could perhaps adopt the not all such unsupported value judgements. One could perhaps alfare ${ }^{12}$ as the basis of a value judgment. Even if one were to do so, however, it would still not follow that a longer structure of production is superior to a shorter one. not imply less economic growth than an elongated one, but the only rational way to determine what degree of roundaboutness will maximize a person's economic welfare is to consult his internal rate of return, or time preference. But this is the very issue under debate: the high time preference person will maximize economic welfare more from immediate consumption than from later gratification (a flatter triangle), while the diate consumpite situation holds true for the individual with low time preference.

Since the structure of production is intimately connected in Austrian economics with the genesis of the business cycle, we can profitably close this discussion by considering the implications of tax policy in this regard. First of all, it is clear that a continually changing tax regime will be associated with economic waste and disarray ${ }^{13}$. If government incessantly switches from tax policies that lengthen the structure of production, to those that shorten it,

12 Rothbard [1982, pp. 205-214] has sharply criticized the employment of even so unobjectionable a goal as this, when employed by Ludwig von Mises.

13 But this will not be exactly equivalent to an Austrian business cycle. States Garrison [1989, 81: p. 8]: «The government implements all sorts of policies and programs in the form of taxes and subparticular good to be above or below its market level. Interventions in the form of taxes and subsidies, price floors and ceilings, tariffs and quotes are, from a narrowly economic point of view, permanent in their effects on resource allocation. A subsidy to home building, for instance, will re sult in a larger-than-otherwise investment in housing so long as the subsidy is in effect. It is possible, of course, that some regulatory schemes can create a political dynamic that eventually result in deregulation. Government enforced cartelization of the airlines, for example, led to an eventuin deregulation. Governmenters of the cartel, which eroded the political al competing away of monopoly profits by the members of the cartel, which eroded the political support for continued regulation. The political forces for deregula interventions by government apart from considerations of such political
have a certain permanence about them». and then back again, resources shall be needlessly wasted. This will occur in a process akin ${ }^{14}$ to the malinvestment which takes place in the boom period, alternating with the cleansing depression of the Austrian business cycle [ROTHBARD, 1975].

However, if the state remains steadfast with any one tax policy, whatever it is, there is no reason to believe, based on the above analysis, that it can set forth a process similar to the Austrian business cycle. Yes, as we have seen, any given fiscal system can lengthen or flatten the investment triangle. And this can certainly have deleterious effects on the economic welfare of the peo$\mathrm{ple}^{15}$. But unlike inflation, this would be a once and for all change in the structure of production, one which could endure, as long as the tax is unaltered. This, of course, is in sharp contradistinction to the alterations to the triangle necessarily brought about through inflation.

\section{APPENDIX: A geometrical analysis of the Austrian structure of production triangle}

In neoclassical economics, capital is typically depicted as " $K$ ", and inserted into an equation. By categorizing it in this manner, the traditional economist states that capital is homogeneous, a "blob" which can in effect be inserted into the production process at any point.

For the Austrians, matters are quite different. In this perspective, capital is heterogeneous; it can only be switched from one sector of the structure of production to another by overcoming the additional costs of making it fit in with the land, labor and capital in its new surroundings. As well, there is such a thing as a structure of production, something its new surroundings. As well, there is such
ing from neoclassical analysis.

Consider figure 1 , for example. Here, land and labor, the originary factors of production are combined in the manufacture of a capital good does the economic actor go out and create a consumption good. The capital good is good, as area 1 (the only and therefore lowest stage of capital), and consumption is shown as C.

14 Tax changes will be "akin" to the Austrian business cycle in that malinvestment occurs in both cases. However, there are important differences. In Garrison's [1989, pp. 7-8] terminology the upturn of the Austrian business cycle is caused exogenously, while the downturn is endogenous. In the case of tax changes, in contrast, both the upturns and downturns would be exogenous. In this sense, the present analysis of tax alterations is similar to the monetarist explanation of the business cycle.

is A too flat a triangle (compared to the one which would result in the absence of taxes) will reduce the growth rate below that which would maximize the economic well being of the citizenry. But too steep a triangle would lower economic welfare but putting off, too far into the future, their consumption activities. And further, the higher the taxes, ceteris paribus, the more harm is done to the society. 
Figure 1: A simple two stage structure of production triangle

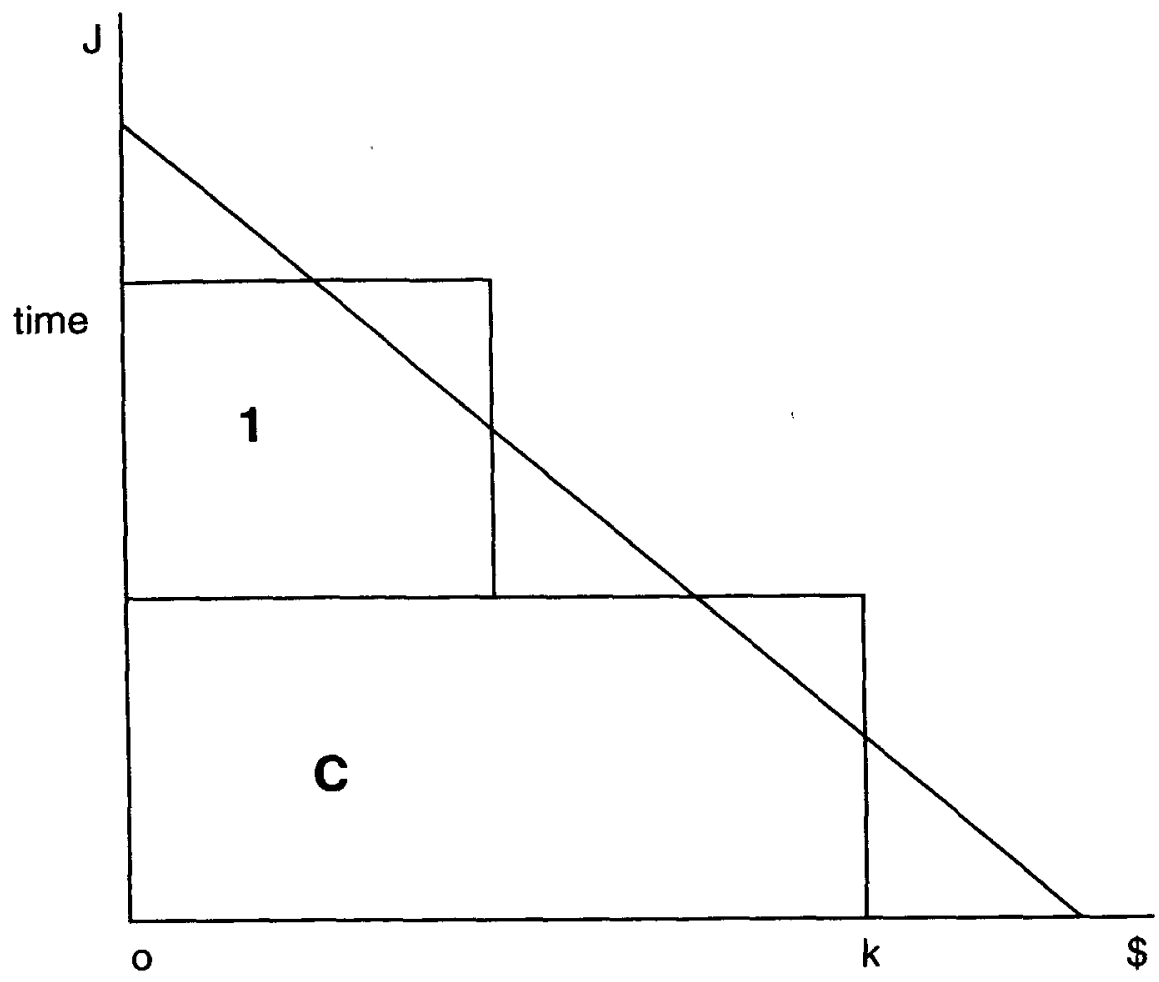

OJK is the triangle

For example, Robinson Crusoe, instead of trying to grab a fish with his bare hand as does a bear, first knocks down a tree branch and fashions a stick for himself; with its aid, he then captures a fish. The 1 stands for the stick, and the $C$ for the fish.

Figure 2 depicts a slightly more complex economy. Here, there are three stages of production: the highest is labeled 3, the intermediate, 2, and the lowest, 1; again, C stands for consumption. For example, 3 might indicate planted wheat, 2 , harvested wheat, 1, flour, and $\mathrm{C}$, bread. At each stage, the services of more land and labor are added to the increasingly valuable capital at the succeeding lower stages, until the process culminates in consumption, $\mathrm{C}$.

Figure 2:

A more complex four stage structure of production triangle indicating bigb time preference

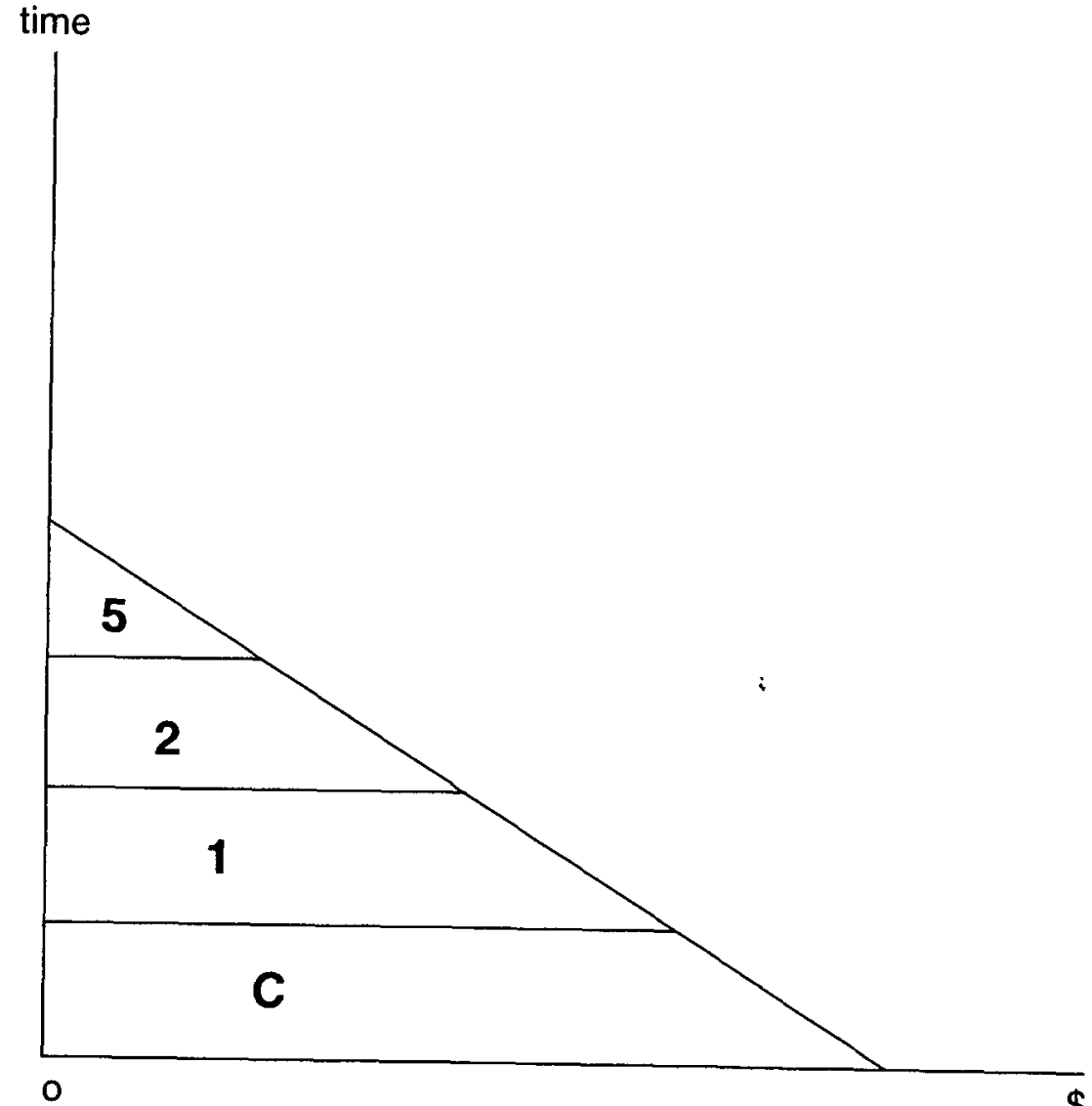


Figure 3 indicates an economy with 5 stages of production. It has been drawn so as to show a structure of production with the same area as in figure $\Pi$. This means that the societies II and III are equally wealthy; however, the two groups of people choose to allocate their wealth differently with regard to saving and investment. Consumption, and the lowest stages of production, areas 1 and 2, are larger in III than in two. In contrast, II has a larger production area 3 , as well as areas 4 and 5 , which are completely missing from III.

Figure 3:

A more complex six stage structure of production triangle indicating low time preference

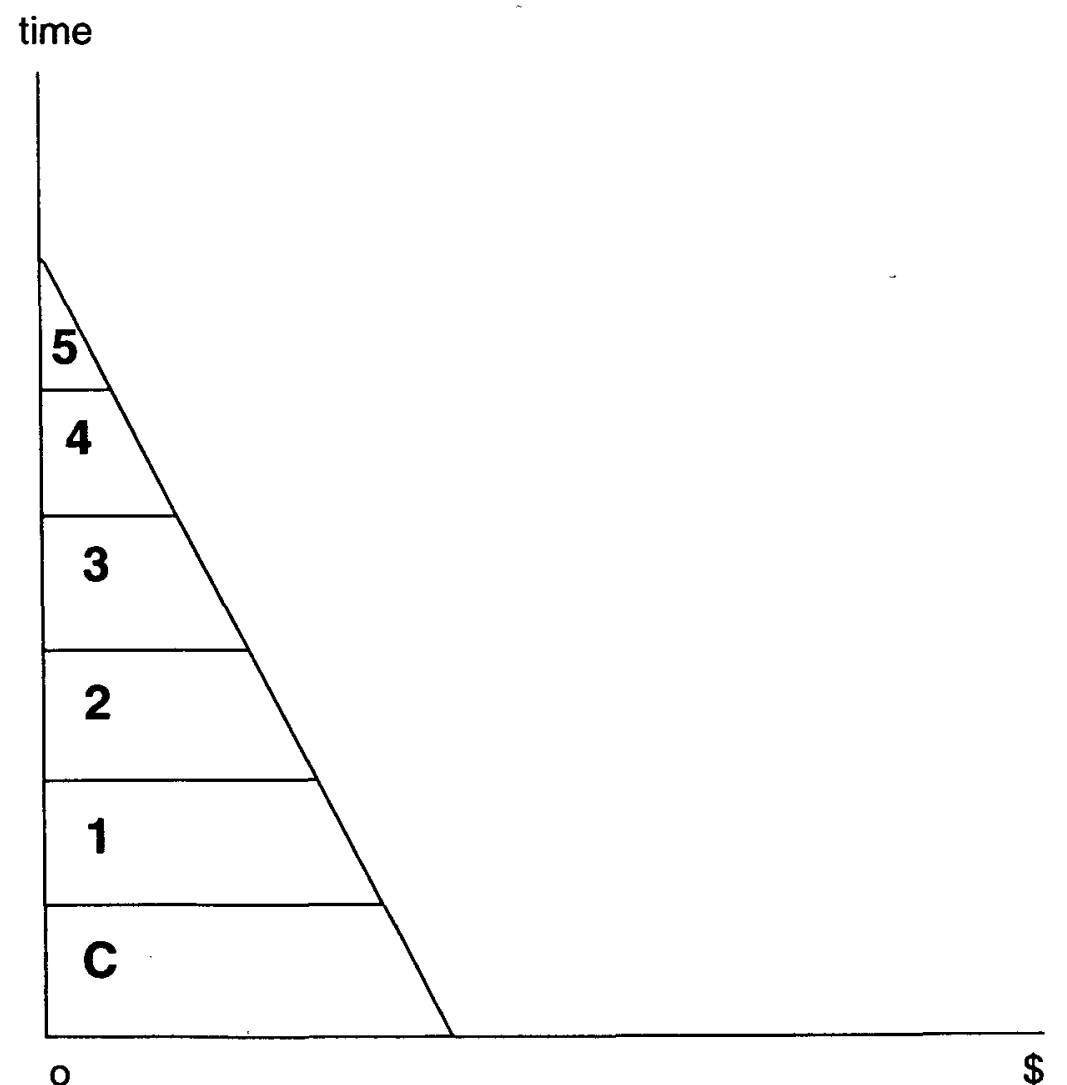

Why the difference between the two? In the Austrian view, this is entirely due to differing rates of time preference (for money or goods in the present as opposed to the future). The economic actors in II are more impatient than those in III. For III, think young children with their noses pressed against the candy store window, who want those sweets now, and would be willing to trade a large amount of money due to them only in the future for this privilege in the immediate present; or picture retired people, who want to enjoy their few remaining years: they emphasize present consumption vis a vis the future consumption which will emanate from present investment. For II, think of young adults or immigrants, saving for a more prosperous future. They are willing to undertake a loss in present consumption to achieve a wealthier future. People in III might conceivably lend money, but the interest rate would have to be high, indeed, to tempt them into such behavior; more likely, they will be borrowers. Similarly, those in II might, conceivably, borrow, but the rate of interest would have to be very close to zero; at any "normal" market rate, they will far more likely be lenders.

In the text, a flat structure of production refers, then, to III, while a steep curve refers to II. This can clearly be seen in figure 4, where II and III are juxtaposed one upon the other.

\section{Figure 4:}

A comparison of the low and bigb time preference structure of production triangles

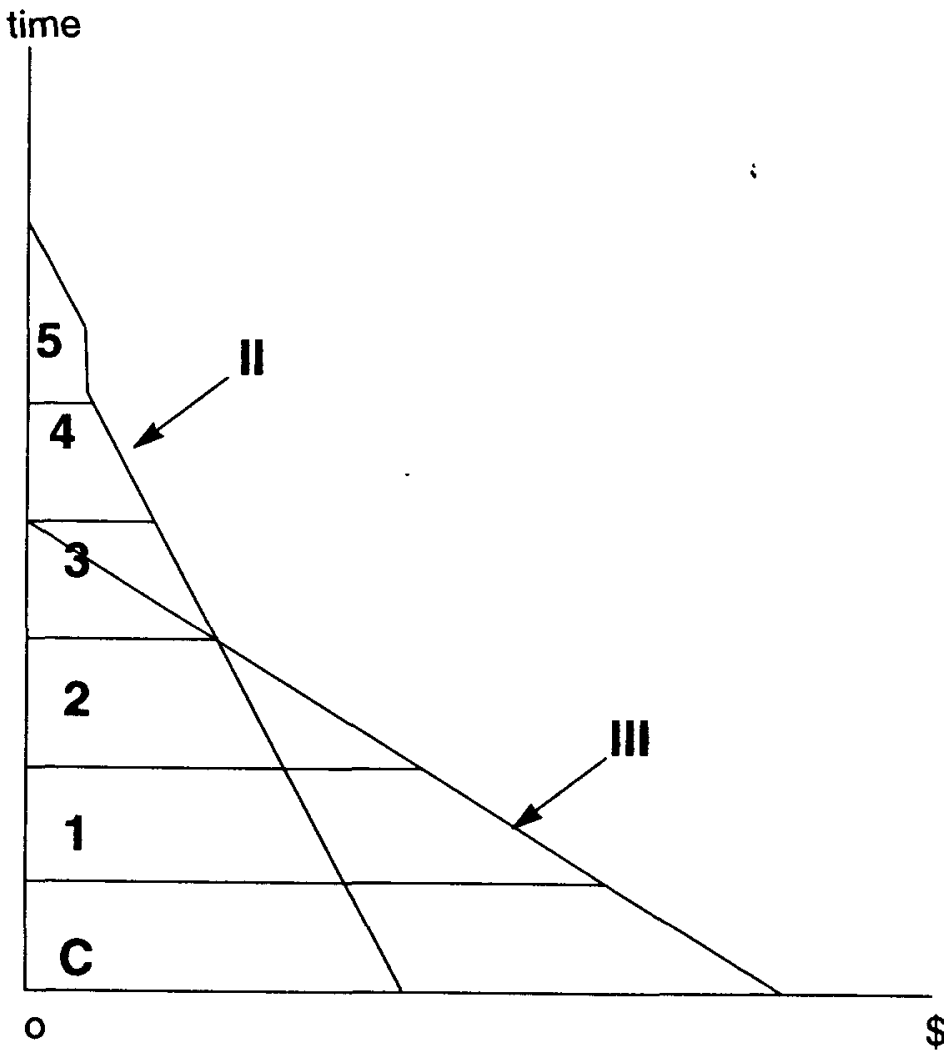


In a nutshell, the Austrian business cycle theory posits that the economy is as depicted in III. The central bank then engages in monetary expansion, which drives the interest rate below its market rate, falsely indicating to entrepreneurs that II is the optimal structure of production. They then open up levels 4 and 5. But the people's time preferences have not changed; they are still consistent only with III. When the central bank stops its inflationary policy, as, ultimately, it must, if it is not to mire the economy in hyperinflation, the investments in levels 4 and 5 are then exposed as resource misallocations. These are wiped out in a spate of bankruptcies which always impacts more heavily in the higher (more basic) order: of production, heavy investment, during the cleansing recession phrase of the business cycle. The Austrian, then, is not an underinvestment theory, as is the Keynesian, but rather a malinvestment explanation of depressions.

Acknowledgements - The author wishes to thank two anonymous referees for their very valuable feedback on an earlier draft of this paper. All remaining errors and inappropriate expressions are his own responsibility.

\section{REFERENCES}

Block, W. 1993, «Canadian Public Finance Texts Cannot Justify Government Taxation: A Critique of Auld \& Miller; Musgrave, Musgrave \& Bird; McCready; and Wolf», Canadian Public Administration, XXXVI, pp. 225-262.

BLOCK, W., 1992, «Comment on McCready, and Maloney on Wealth Taxation», Canadian Public Administration, XXXV, pp. 542-548.

BLOCK, W., 1989, «The Justification of T axation in the Public Finance Literature: A Critique of Atkinson and Stiglitz, Due, Musgrave and Shoup», Fournal of Public Finance and Public Cboice, 3, pp. 141-158.

BÖHM-BAWERK, E., 1921/1959, Capital and Interest, South Holland Illinois, Libertarian Press.

BroWNING, E. K. - JOHNSON, W. R., 1979, «The Distribution of the Tax Burden», Washington D.C., American Enterprise Institute.

Browning, E. K.- Johnson, W. R., 1984, «Taxes in the United States» in Block, W. and WALKER, M. (eds) Taxation: An International Perspective, Vancouver, The Fraser Institute.

BUCHANAN, J. M., 1984, «The Limits of Taxation» in BLOCK, W. - WALKER, M. (eds), Taxation: An International Perspective, Vancouver, The Fraser Institute.

Buchanan, J. M. - BrennaN, G., 1980, The Power to Tax: Analytical Foundations of a Fiscal Constitution, Cambridge, Cambridge University Press.

Cal houn, J. C., 1953, A Disquisition on Government, New York, Liberal Arts Press. DUE, J. F., 1963, Government Finance: An Economic Analysis, Homewood Illinois, Irwin.

FELDSTEIN, M. (ed.), 1980, The American Economy in Transition, Chicago, University of Chicago Press.

FERRARA, P. J., 1980, Social Security: The Inberent Contradiction, San Francisco, Cato Institute.

GARRISON, R., 1989, «The Austrian Theory of the Business Cycle in the Light of
Modern Macroeconomics», The Review of Austrian Economics, III, 1989.

HAYEK, F. A., 1932, Prices and Production, London, The London School of Economics.

HAYEK, F. A., 1941, The Pure Theory of Capital, Chicago, The University of Chicago Press.

KALDOR, N., 1932, «The Economic Situation in Austria», Harvard Business Review, 11 , pp. 23-34.

LaCHMANN, L., 1956, Capital and its Structure, London, The London School of Economics.

MACHluP, F., 1935, «The Consumption of Capital in Austria», The Review of Economic Statistics, 17, pp. 13-19.

Musgrave, R. A. - Musgrave, P. B., 1959, Public Finance in Theory and Practice, New York, McGraw-Hill.

Rothbard, M. N., 1970, Man, Economy and State, Los Angeles, Nash.

RotHBARD, M. N., 1977, The Reconstruction of Utility and Welfare Economics, New York, Center for Libertarian Studies.

Rothbard, M. N., 1975, America's Great Depression, Kansas City, Sheed and Ward. Rothbard, M. N., 1978, For $A$ New Liberty, New York, Macmillan.

Rothbard, M. N., 1982, The Etbics of Liberty, Atlantic Highlands, N.J., Humanities Press.

Shoup, C. S., 1969, Public Finance, Chicago, Aldine.

vON MISES, L., Human Action, Chicago, Regnery, 1966.

vON Mises, L., Theory and History, New Rochelle, N.Y; Arlington House, 1969. 